\title{
Políticas de Composto ${ }^{1}$
}

\author{
Compost politics
}

\section{Gabrielly Merlo de Souza* ${ }^{1}$}

Palavras-chave: Composto; Solo; Cosmopolítica; Assemblage; Ética ecológica.

Keywords: Compost; Soil; Cosmopolitics; Assemblage; Ecological ethics.
Resumo: A compostagem, enquanto uma prática ecológica de reaproveitamento de restos de cozinha e de produção de solo orgânico, aparece como um componente central no ideal de regeneração ambiental dos moradores dos sítios ecológicos onde minha etnografia foi realizada. Compostar é tido como uma arte, ela é capaz de reunir diferentes organismos que, com interesses distintos, e às vezes antagônicos, participam ativamente do longo processo de "fazer solo", reconstruir paisagens, regenerar ambientes degradados. Neste artigo lanço um olhar sobre o composto e seus múltiplos agenciamentos. O objetivo é apresentar como a arte de compostar oferece imagens vívidas de encontros multiespécies e de futuros ecológicos possíveis que, todavia, nos empurram para fora da noção ocidental naturalista sobre "o que faz o mundo natural" e "o que faz a política".

\begin{abstract}
Composting, as an ecological practice of reusing kitchen waste and producing organic soil, appears as a central component in the ideal of environmental regeneration of the inhabitants of the ecological sites where my ethnography was carried out. Composting is seen as an art, it is capable of bringing together different organisms that, with distinct and sometimes antagonistic interests, actively participate in the long process of "making soil", reconstructing landscapes, regenerating degraded environments. In this article, I take a look at the compound and its multiple assemblages. The aim is to present how the art of composting offers vivid images of multi-species encounters and possible ecological futures that nevertheless push us outside the Western naturalistic notion of "what makes the natural world" and "what makes politics".
\end{abstract}

\footnotetext{
${ }^{1}$ Recebido em 15/12/2020. Aceito em 10/07/2021.

* ${ }^{1}$ Doutora em Antropologia pelo Programa de Pós-Graduação em Antropologia da UFMG. E-mail: gabmerlo@gmail.com
} 


\begin{abstract}
"Organisms are ecosystems of genomes, consortia, communities, partly digested dinners, mortal boundary formations. Even toy dogs and fat old ladies on city streets are such boundary formations studying them 'ecologically' would show it". (Donna Haraway, 2016, p. 31)
\end{abstract}

\title{
Introdução
}

Opresente artigo é parte de uma pesquisa realizada entre os anos de 2015 e 2020 nos distritos de São Gonçalo do Rio das Pedras e Lapinha da Serra, Minas Gerais, onde membros de um coletivo denominado Instituto de Permacultura Ecovida São Miguel residem em pequenos sítios voltados para realização de atividades experimentais e propostas ecológicas de cunho faça-você-mesmo envolvendo técnicas de bioconstrução, tratamento dos resíduos domésticos, produção de energia, entre outras "gambiarras" destinadas à implementação de uma habitação ecológica ou sustentável. No bojo das discussões contemporâneas sobre o impacto humano no planeta, essas moradias acabam por se tornar "vitrines" ou espaços de amostragem que inspiram soluções e alternativas ecológicas para uma série de situações e necessidades básicas do dia-a-dia.

Tomar os sítios permaculturais como "espaços de amostragem" se aproxima da ideia de ecologias de demonstração (ecology of demonstrations) que tomei de empréstimo de Markus Rudolfi (2017). Ecologias de demonstração, segundo o autor, se pautam em projetos e em soluções aplicáveis no dia-a-dia que visam contornar problemas práticos (como saneamento, abastecimento de água, uso de energias, moradia, etc.). Para o autor, esses experimentos apontam para potenciais indicativos em ecologias-mais-que-humanas ${ }^{2}$ por problematizarem, por exemplo, a escolha de materiais de construção ao construir uma casa, ou ao evitar consequências nocivas para outras espécies (no futuro) relativas ao nosso modo de habitar. Em suma, as ecologias de demonstração, na definição do autor, estabelecem modos de alcançar uma sustentabilidade radical que acaba por constituir prefigurações sociotécnicas. Rudolfi (2017) explica que experiências do tipo são muito diversas e podem ser entendidas como demonstrativas por não serem de caráter deliberativo, ou seja, não competem por hegemonia. Ao contrário, tratam-se de práticas experimentais e de âmbito doméstico; e, ao focarem na resolução de

2 Rudolfi (2017, p. 4) recorre ao termo "mais-do-que-humana" (more-than-human) definindo-o da seguinte maneira: "By 'more-than-human' I refer to a concept introduced by Donna Haraways 'multispecies' approach that puts other-than-human companions (such as dogs or bacteria) on the interdisciplinary research agenda and asks for the multiple ways in which they are connected and intermingle (see Haraway, 2008)".

Caderno Eletrônico de Ciências Sociais, Vitória, v. 8, n. 2, pp. 130-152, 2020. 
problemas pontuais, deixa-se escapar definições mais amplas acerca de objetivos e sentidos estratégicos únicos.

A etnografia que realizei nos sítios permaculturais resultou na escrita da tese "Envolver o que nos envolve. Permacultura e sítios ecológicos em paisagens multiespécies na Serra do Espinhaço" (SOUZA, 2020). O presente artigo foi baseado, mais propriamente, no capítulo 06 da tese em que tratei do curso Planejamento de Espaços Prósperos: Ambiente Saudável e Agroecologia (PEP), realizado no sítio Céu e Terra, distrito de São Gonçalo, em 2019. Contudo, antes de seguir aqui com a apresentação dos atores e do curso do PEP, gostaria de assinalar alguns pontos gerais e indicar alguns referenciais que em grande medida influenciaram minhas escolhas ao longo da escrita da tese.

Minha aventura etnográfica entre permacultores e permaculturas - e entre outros atores (ou actantes, na definição latouriana) envolvidos na pesquisa - culminou no que considero ter sido um exercício narrativo e especulativo inspirado em estudos multiespécies. ${ }^{3}$ Treinar tal escrita me despertou para a consideração dos agenciamentos não exclusivamente humanos em voga na perspectiva ecológica dos meus interlocutores e no próprio saber/fazer ambiental. As experiências de campo nos sítios permaculturais e as lições apreendidas sobre "fazer solo", compostar, regenerar ambientes, etc., me convidaram a olhar a prática de compostagem e os seus agenciamentos enquanto uma arte - ou um modo de fazer política em tempos de Antropoceno. Como colocado tantas vezes pelos meus interlocutores, a ação de compostar é também uma resposta ética às crises emergentes da modernidade (crise climática, energética, dentre outras). Neste sentido, reflito sobre como processos bioquímicos e agenciamentos múltiplos (incluindo humanos e não humanos) em jogo na ação de degradação de materiais, por fim, acabam por conformar um sentido de ética ecológica e de sustentabilidade não centrados no humano ou na divisão moderna entre mundo natural e mundo social.

Os saberes ligados à regeneração do solo consistem em técnicas e conhecimentos extraídos da permacultura, da agroecologia, das ciências do solo e, como os moradores dos sítios relatam, o aprendizado desse fazer também se dá pela "observação da natureza" e do contato deles com outros agricultores e agricultoras da vizinhança. Portanto, trata-se de uma miscelânea de saberes que visam a restauração da vida de solos degradados, bem como dos plantios e do manejo livre de insumos externos

3 Estudos multiespécies é entendido aqui como um dos programas de que a antropologia participa em direção a uma abordagem ampliada de social para além do humano (KIRKSEY \& HELMREICH, 2010).

Caderno Eletrônico de Ciências Sociais, Vitória, v. 8, n. 2, pp. 130-152, 2020. 
e agroquímicos. A regeneração compreende um trabalho em que humanos e organismos do solo atuam para fins de revitalização da vida edáfica; mas regenerar, sobretudo, significa (re)construir a possibilidade de (re)integração e de convivência entre os humanos e os não humanos. É importante enfatizar que esse modo de manejar o solo, na perspectiva dos meus interlocutores, não objetiva apenas finalidades agrícolas ou de conservação ambiental. O modo como permacultores e permacultoras dedicam tempo ao solo (cf. BELLACASA, 2017) expressa, tal como procurei mostrar em minha pesquisa, um sentido de ética do cuidado da terra e uma forma de amar outras formas de vida não humana (cf. TSING, 20194).

Dentre as variadas técnicas de regeneração ambiental utilizadas pelos meus interlocutores, para fins deste artigo, darei destaque à compostagem e aos seus múltiplos agenciamentos. Para tanto, o texto segue, primeiramente, apresentando o curso onde realizei uma parte do trabalho de campo, quando apresento os pressupostos políticos-teóricos dos idealizadores do curso; em seguida discuto a arte da compostagem em diálogo com algumas noções da Antropologia; então, descrevo a montagem de uma composteira e a participação das minhocas nesses fazeres.

\section{Construir "Espaços Prósperos"}

No texto de divulgação do curso, o PEP é definido como uma metodologia prática e uma ferramenta:

O PEP é uma metodologia prática que foi estruturada ao longo dos anos de experiência e atuaão do Sítio Céu e Terra e está fundamentada em Permacultura, Agroecologia, Geobiologia, Homeopatia, Educação do Campo e Saude Integral. [...] Apresentamos uma compilação de ferramentas, técnicas e materiais de planejamento, orientação e práticas no campo, no formato de curso, workshop ou programa extensivo.

O curso foi organizado em parceira com os Departamentos de Fitotecnia e de Educação da Universidade Federal de Viçosa (UFV), através do Programa de Extensão "Divulgação das Plantas Medicinais, da Homeopatia e da Produção de Alimentos Saudáveis", sob coordenação dos professores Vicente Casali e Fernanda Andrade. A proposta que o PEP traz ao público mais amplo consiste em compartilhar informações teóricas, mas, principalmente, conteúdo técnico e ferramentas que contribuam "para a

4 Me refiro mais propriamente ao texto "Arte da inclusão, ou, Como amar um cogumelo", capítulo 2, p. 43.

Caderno Eletrônico de Ciências Sociais, Vitória, v. 8, n. 2, pp. 130-152, 2020. 
criação de espaços prósperos, saudáveis em harmonia com a natureza" (...) "rumo ao bem viver". 5

Os módulos oferecidos no PEP em 2019 foram: "Introdução à Permacultura e educação no campo"; "Geobiologia e Design Permacultural"; "Agroecologia e Homeopatia na Agricultura"; e "Saúde Integral, Fechamento do Design e Celebração". Todos eles foram ministrados pelos facilitadores e moradores do sítio, Euro Caetano e Mayan Maharishi, que também foram os organizadores e idealizadores do evento. Em alguns dos encontros, participantes vindos de outras localidades foram convidados como palestrantes para tratarem de temas específicos.

O programa de ensino do PEP foi estruturado em diálogo com os conhecimentos agroecológicos e da permacultura, estando também alinhados a uma série de outros movimentos e filosofias que trabalham com perspectivas ecológicas afins. Os idealizadores do curso compreendem que ao recorrer à diversidade de referências estão realizando uma "fusão de conhecimentos" que posiciona a proposta do curso na fronteira das ciências, isto é, o conteúdo teórico transita por diferentes áreas do conhecimento. Como enfatizado muitas vezes ao longo do curso, seus idealizadores não se percebem alheios à ciência, mas tampouco se consideram limitados a ela. ${ }^{6}$ O diálogo entre diferentes conhecimentos (científicos ou não) foi um dos pontos altos do PEP, dado que os organizadores, como é de praxe em eventos ligados à permacultura, realizaram uma espécie de bricolagem de saberes. Colocam-se lado a lado terminologias de base científica junto a noções estranhas ao universo acadêmico.

Em um dos módulos de que tive oportunidade de participar, em meio a discussões acaloradas entre cursistas e facilitadores, questões sobre o futuro dos solos eram trazidas pelos participantes. Junto ao debate provocativo, biscoitos caseiros, chás e café eram gentilmente servidos ao nosso pequeno grupo em uma fria manhã de sábado. Estávamos em plena região do cerrado mineiro. O clima do lugar era convidativo e acolhedor mesmo quando os assuntos debatidos pareciam tão complicados. Almofadas dispostas pelo chão e, atravessando o espaço da sala, uma rede de tecido havia sido estendida de uma parede a outra, disponível para quem preferisse deitar durante as aulas expositivas. Um cachorro ao canto da sala, cujo nome é Alecrim, também um morador do sítio, se manteve

${ }^{5}$ Trecho do texto de divulgação do curso no perfil do Sítio Céu e Terra, retirada na página oficial do Facebook.

${ }^{6}$ Alguns dos conteúdos com os quais lidam, por exemplo, a homeopatia ou a agricultura biodinâmica, apesar de serem já bastante difundidas em todo o mundo, não necessariamente se fundam em evidências científicas ou alcançam consenso na comunidade acadêmica.

Caderno Eletrônico de Ciências Sociais, Vitória, v. 8, n. 2, pp. 130-152, 2020. 
deitado toda a manhã na porta e às vezes parecia nos observar, ele suspirava sempre que os humanos se exaltavam em meio a discussões sobre política. Na mesma sala, uma pequena mesa estava disposta ao centro com alguns livros empilhados para consulta livre, em geral, os livros abordavam temas relacionados à proposta em tela.

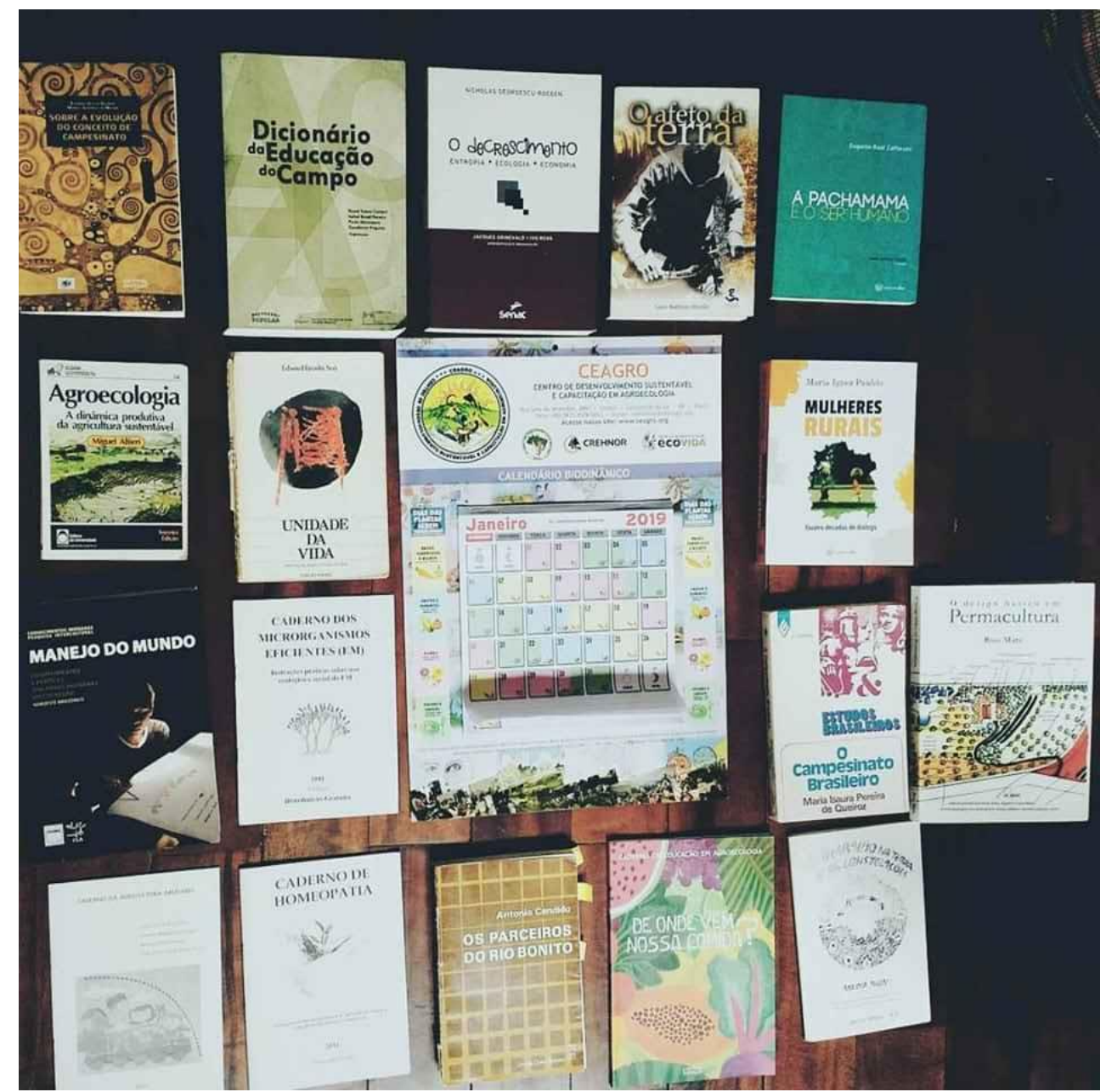

Foto 1: Livros apresentados no PEP 2019. Sítio Céu e Terra. Autoria própria.

Por trabalharem dentro da perspectiva de ciência prática e popular, Euro e Mayan trouxeram duas referências centrais da agroecologia: a agrônoma Ana Maria Primavesi, austríaca nascida na década de 1920 e naturalizada brasileira em 1949; e o agrônomo Miguel Altieri, nascido no Chile nos anos 1950, e que hoje reside nos Estados Unidos, onde é professor na Universidade da Califórnia. Primavesi que viveu até o fim de sua vida no Brasil, trabalhou como professora de Ciências Agrárias na Universidade Federal de Santa Maria, onde também contribuiu para organização de um curso de pós-graduação em agricultura orgânica, tendo, mais tarde, fundado a Associação de Agricultura Orgânica (AAO). 
Ambos, Primavesi e Altieri, têm uma longa trajetória envolvendo projetos e publicações de livros e artigos científicos dedicados a promover a agroecologia pelo mundo, bem como a difundir entre seus colegas de profissão a perspectiva de que o solo é um organismo vivo. Toda a trajetória dos autores se inspira em percorrer essa assertiva, a qual aparece como a base das discussões em muitos de seus escritos, entre os quais, elenquei o trecho abaixo para esclarecimento sobre o que está sendo entendido por organismo vivo:

[...] O solo não é aquilo que a agricultura quimiotécnica pregava, somente um suporte para os adubos, água de irrigação e culturas, mas um organismo vivo, cujo esqueleto é a parte mineral, cujos órgãos são os micróbios que ali vivem e cujo sangue é a solução aquosa que ali circula. Respira como qualquer outro organismo vivo e possui sua temperatura própria. Necessita ele tanto das plantas, como as plantas necessitam dele. (PRIMAVESI, 1964, pp. 13-14, grifos meus)

Pautados muito fortemente na perspectiva daqueles autores, e de outros pesquisadores e pesquisadoras da agroecologia, meus interlocutores nos traziam essa imagem política e povoada do solo. O solo vivo, portanto, seria o componente essencial para alcançar as transformações agroecológicas e a regeneração de ambientes de que tratava o curso do PEP. Essa noção está bem colocada na fala de um dos organizadores que transcrevo abaixo.

Olha só, dentro da ideia de solo, quando a gente fala que o solo é um organismo vivo, que a terra é um ser vivo, a gente parte do princípio de Ana Primavesi que veio traduzir, de uma maneira muito clara para a sociedade, como é que realmente o solo pulsa a vida. $O$ solo equilibrado tem bilhares, trilhares de seres vivos trabalhando ali incessantemente, transformando a terra. (Euro).

O que estava sendo colocado pelos organizadores é o entendimento do solo não enquanto receptáculo de culturas, mas enquanto habitat. Trata-se, aqui, de reconhecer e opor pelo menos dois modos distintos não apenas de trabalhar com, mas de perceber o solo. Na perspectiva dos organizadores do PEP, bem como dos autores acima mencionados, a agricultura ecológica deve privilegiar a atividade biológica do solo e não reduzir o solo aos serviços que presta aos humanos, tal como produzir alimento e mercadorias, por exemplo - perspectiva esta que privilegia a produção. Como dizem meus interlocutores, o tratamento que é dado ao solo irá definir o modo do trabalho por vir. Neste sentido, como o solo é percebido reflete o modo como se trabalha com ele, com as plantas e com o ambiente.

Caderno Eletrônico de Ciências Sociais, Vitória, v. 8, n. 2, pp. 130-152, 2020. 
Entre as ciências que trabalham com análise do solo, dentre elas a agronomia e a pedologia - cujos fundamentos e objetivos podem vir a ser bastante distintos, por vezes, antagônicos - é possível encontrar pesquisadores e pesquisadoras mais explicitamente alinhados à perspectiva da agroecologia, ainda que esse posicionamento seja bastante marginal dentro dessas áreas. É possível encontrar estudos especializados em que o solo não aparece como mero receptáculo de culturas ou substrato para o desenvolvimento vegetal e produção de commodities. E assim, em meio a diferentes perspectivas em disputa, tem crescido o número de pesquisadores atentos à multiplicidade de fatores a se levar em conta no trato dos solos. Essas clivagens internas às ciências agrárias e do solo têm levado pesquisadores a denunciar o "estilo reducionista de seus colegas de área" - aqui parafraseando Latour (2014).

Em etnografia com cuidadores do solo, entre eles alguns soil scientists, a antropóloga Maria Puig de la Bellacasa (2017) destaca que tem crescido o espaço para entendimentos da ontologia dos solos enquanto uma comunidade viva, ${ }^{7}$ no lugar de perspectivas reducionistas que o tomam como uma matéria que presta serviços aos humanos. Cientistas do solo, tais como Santos e colaboradores (2017), por exemplo, observando a carência de uma abordagem nas ciências que trate o solo como um ecossistema (sistema complexo), vêm difundindo através de cursos e disciplinas acadêmicas essa perspectiva. São pesquisadores que têm investido na difusão da compreensão do solo como organismo vivo e, para isso, materiais didáticos e análises instigantes em torno dessa temática têm sido oferecidos por membros dessa comunidade agroecológica e de estudiosos do solo.

[o solo é] responsável por manter a vida no planeta através da regularização de seus processos biológicos, químicos e físicos além da produção de alimentos para suprimento da população humana. Dentre esses podemos citar: (i) os processos biológicos: controle de patógenos, biomassa e respiração microbiana; (ii) os processos químicos: decomposição da matéria orgânica, ciclagem de nutrientes, produção de húmus, ácidos orgânicos, controle do $\mathrm{pH}$ e capacidade de troca catiônica; e (iii) processos físicos: formação de agregados, textura, porosidade, densidade, profundidade e

7 Bellacasa (2015) chama atenção, no entanto, que embora cientistas do solo considerem o solo uma comunidade viva, em geral, o ser humano se apresenta principalmente como uma "irrupção desequilibrada", ela diz, nos ciclos ecológicos do solo, ou mesmo uma vítima no caso da poluição do solo, ao invés de um membro da comunidade do solo.

Caderno Eletrônico de Ciências Sociais, Vitória, v. 8, n. 2, pp. 130-152, 2020. 
infiltração da água no perfil do solo (Moreira et al., 2013). (SANTOS et al., 2017, p. 15)

Pautados na prática e na ciência popular, agroecologistas vêm atuando diretamente junto a agricultores familiares e em frentes institucionais para fomentar esse tipo de entendimento, sobretudo, visando a recuperação dos solos. ${ }^{8}$ Nessa linha, pesquisadores, ativistas ecológicos e toda uma nova geração de agricultores têm se concentrado em práticas de retomada e valorização de formas de manejos tradicionais, todavia, esse movimento é um modo de resistir ao avanço do agronegócio. Esse movimento também investe no fomento de redes de trocas de sementes crioulas, na promoção da cultura cooperativista, dentre outras ações e iniciativas de alcance global e local. Por sua vez, em direção contrária à emergência do ativismo do solo, a agricultura quimiotécnica, como define Primavesi (1964), vem promovendo a perspectiva do solo como receptáculo de culturas, e abusa dos agroquímicos e de maquinários que compactam o solo. Esse modelo trabalha no fomento de plantios monoculturais, os quais historicamente vêm solapando a diversidade de práticas ecológicas e tradicionais de cultivos biodiversos. Cenários de tensionamentos como estes trazem muitas imagens do espectro das crises ecológicas que hoje vivenciamos no planeta.

A proposta do PEP se funda nos princípios agroecológicos. E, em seu conjunto de princípios, promover a vitalidade do solo, ao meu ver, compreende $o$ que os facilitadores do curso estão chamando de prosperidade, palavra que aparece no próprio nome do curso. Um ambiente próspero é aquele cujos solos estão vitalizados e, por isso, há qualidade de vida para os humanos e não humanos que nele habitam e dele dependem. Naquela manhã, por estarmos ali reunidos em torno desse ideal de prosperidade, a sensação era de que nós, cursistas, havíamos firmado um pacto agroecológico: perceber o solo como um ser vivo.

Quando adentramos as assembleias multiespécies do solo começamos um trabalho difícil, porém, crucial: descobrir como a política e a ecologia podem ser mais do que a conjunção dessas duas palavras: ecologia e política. Em muitos de seus trabalhos, Latour $(2004 ; 2001)$ nos provoca a repensar o que seja ecologia política. Em sua tese, o autor se refere aos movimentos ecológicos e ambientais quando estes decidem juntar "natureza" e "política" sem, contudo, repensar inteiramente seus componentes. Trata-se de uma política bifocal, diz Latour (2004, p. 40),

8 Para experiências neste sentido, ver o "Sistema Agroecologia em Rede" (https://www.agroecologiaemrede.org.br/); o movimento de Articulação Nacional de Agroecologia (ANA) (www.agroecologia.org.br); a plataforma coletiva latino-americana "Alianza Biodiversidad" (http://www.biodiversidadla.org/); dentre outras iniciativas nacionais e internacionais que difundem a agroecologia de base campesina.

Caderno Eletrônico de Ciências Sociais, Vitória, v. 8, n. 2, pp. 130-152, 2020. 
com base na Constituição Moderna: "um foco direciona-se para a política e o outro, sob o nome de natureza, torna impotente o primeiro". Como o filósofo também discute em outra passagem: "todo o problema da ecologia, o problema geral das questões da natureza está aí: Quem conta? Quem é importante? Como organizar esses seres? Como atribuir a eles propriedades que permitam compreender quem é o mais importante para poder organizálos e saber qual deles deve ser considerado?" (LATOUR, 2001, p. 33).

Por conta do modo como os facilitadores do curso colocavam para nós, cursistas, o problema do solo, o fato de que pare eles o solo é um organismo vivo, me ocorreu perguntar: como organismos não-humanos são posicionados no debate sobre o futuro da agricultura? Eles são entendidos como participantes ativos ou meros componentes externos desse modo de fazer? Dedicar tempo e atenção ao solo como faz um agroecologista; lutar pela reforma agrária como faz um militante; realizar estudos científicos a partir da amostragem de solo em laboratório como faz um pedólogo; enfim, essas práticas seriam equivalentes ${ }^{9}$ para as políticas do solo? Como o modo de interagir, manejar ou politizar o solo demarca diferentes perspectivas e imagens? Como isso repercute, em larga escala, nos modelos de agricultura e no modelo hegemônico de produção de matéria prima?

A questão do que seria do mundo da natureza, do mundo da política ou do mundo da ciência não é mais - ou não deveria ser - sobre juntar ecologia e política, mas uma "questão cosmopolítica", como postula a filósofa Isabelle Stengers (2018). Sobre isso, Latour (2001, p. 40) sintetiza a cosmopolítica stengeriana nos seguintes termos: "o que importa na noção de natureza não é o seu caráter ontológico, isto é, o fato de estar relacionada a objetos, mas o fato de permitir estabelecer ligações entre incomensuráveis". E este é o ponto de onde pretendo partir daqui adiante.

Em nossas aulas-práticas junto à comunidade do solo fui convocada pela experiência de manejo agroecológico e permacultural a introduzir os não humanos seriamente na política. As minhocas e os demais habitantes daquela comunidade, agora sim são participantes ativos da ecologia política nos termos com que Latour a define (2004, p. 343, grifos meus):

Com a ecologia política, entra-se na verdade em outro mundo, aquele que não tem mais por ingredientes uma natureza e culturas, que não pode mais, então, simplificar a questão do número de coletivos, unificando-a pela natureza, nem complicá-la, aceitando uma multiplicidade inevitável e

${ }^{9}$ A expressão foi utilizada por Euro, meu interlocutor, e aqui a reproduzo por ela exprimir muito bem a ideia de que práticas ou pensamentos que, a princípio, parecem diferentes não deveriam obedecer a uma hierarquia de prioridade ou importância, pois teriam "importâncias equivalentes".

Caderno Eletrônico de Ciências Sociais, Vitória, v. 8, n. 2, pp. 130-152, 2020. 
definitiva de culturas incomensuráveis. Entramos num mundo composto de realidades insistentes, em que as proposições dotadas de hábitos não aceitam mais fazer calar as instituições encarregadas de acolhê-las, nem serem acolhidas ficando mudas sobre a realidade de suas exigências. $O$ exterior não é mais tão forte para reduzir ao silêncio o mundo social, nem tão fraco para se deixar reduzir a insignificância. No sentido novo que demos a esta palavra, as entidades excluídas exigem que o coletivo se apresente e se represente no seu apelo, isto é, arrisque de novo a sorte de todas as suas instâncias representativas.

Se havia alguma dúvida sobre como fazer ecologia política sem necessariamente ficarmos atados ao domínio dos humanos, a resposta que Euro, facilitador da aula naquela manhã, nos oferecia me parecia valiosa. Ele dizia: "faça cobertura vegetal", isto é, faça composto! A foto a seguir mostra organismos e materiais "fazendo ecologia política" no minhocário do Sítio Céu e Terra.

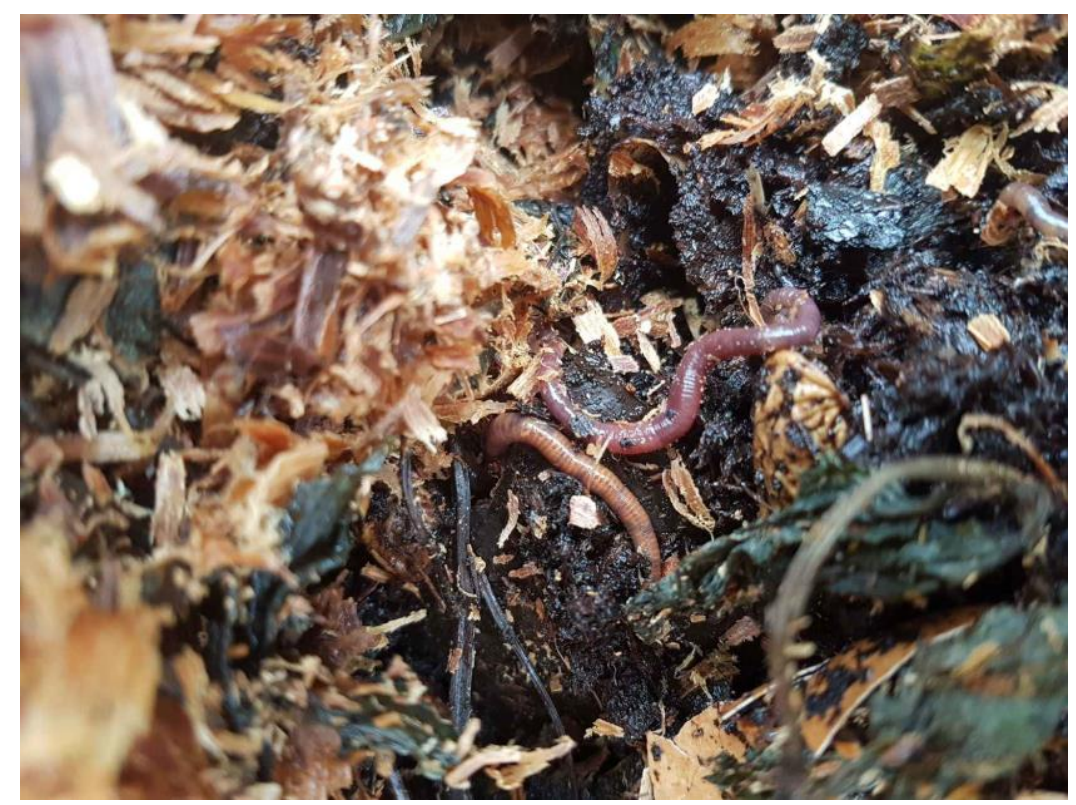

Foto 2: Materiais e organismos em decomposição. Sítio Céu e Terra (São Gonçalo do Rio das Pedras, MG). Autoria própria.

\section{A arte da compostagem}

"Eating, feeding and composting are transformative and always involve changes". (Abrahamsson \& Bertoni, 2014, p. 138) 
Em geral, compostar é um processo de decomposição de material orgânico, podendo ser restos de alimentos, galhos e folhas, fezes humanas ou de outros animais. Independentemente do tipo de material, a compostagem sempre envolve o trabalho de microrganismos, sobretudo fungos e bactérias que degradam a matéria orgânica transformando-a em húmus. Ao material que está sendo compostado, pode-se misturar minhocas ou outros materiais como serragem, terra, galhos, folhas secas, etc., mas, para que todo o processo ocorra corretamente, alguns cuidados são requeridos no manejo. Por isso, é também um pouco sobre cuidados na relação dos humanos com os agentes não-humanos que irei tratar nesta sessão.

Geralmente, permacultores se dedicam a ensinar outras pessoas iniciantes como fazer sua própria composteira. Manuais são escritos e compartilhados de forma impressa e digital. Da parte do Instituto de Permacultura Ecovida São Miguel, coletivo que foi foco da minha pesquisa no doutorado, encontrei na internet diferentes materiais didáticos confeccionados por seus membros envolvendo o assunto da compostagem. Nesses materiais, o ensino de como fazer compostagem costumava vir acompanhado de discussões sobre tecnologias ecológicas. Em geral, os textos que explicam a compostagem são também relatos pessoais sobre a experiência de compostar materiais.

Divulgar e ensinar a arte da compostagem tem se tornado uma via para a construção de uma cultura ecológica cotidiana que de uma prática individual doméstica, nos últimos anos, se tornou foco de movimentos tanto locais, quanto globais. ${ }^{10} \mathrm{Em}$ geral, o que me pareceu mais notável em relação a este universo é o fato do ensino da compostagem remeter ao conhecimento prático e ao engajamento pessoal com o experimento, antes de ser apenas um saber técnico mediado por instituições de ensino. Portanto, é uma prática que envolve uma certa paixão e um olhar sensível para os organismos e materiais, além de uma certa habilidade com o manejo. Por isso, ao longo dessa pesquisa, passei a entender a compostagem como uma "arte", em sentido amplo, por envolver transformações, habilidades, experiências.

Os composteiros, praticantes de compostagem, geralmente observam e participam ("observação participante") de todo o processo de compostar, desde a montagem do equipamento até as etapas posteriores. Esse

\footnotetext{
10 Para exemplos de organizações coletivas que visam construir um movimento comunitário em torno da compostagem, ver: projeto Composta São Paulo (https://www.compostasaopaulo.eco.br/); movimento Rust Belt Riders (https://www.rustbeltriders.com/); Fundação Internacional Composting Council (www.compostfoundation.org/); projeto MASSALAS (https://massalas.com.br/), dentre outros.
}

Caderno Eletrônico de Ciências Sociais, Vitória, v. 8, n. 2, pp. 130-152, 2020. 
acompanhamento é pré-requisito para uma compostagem bem-sucedida, pois evita que o cuidador da composteira tenha surpresas futuras com seu experimento. Caso o processo de decomposição fuja do esperado, algo que pode facilmente acontecer, o composto gerará mal cheiro ou mesmo pode vir a desenvolver microrganismos patogênicos, dentre eles a salmonela, por exemplo. É importante saber que a compostagem não é um experimento puramente mecânico, mas um sistema complexo ou vivo; seus resultados podem ser lidos pelos humanos como benéficos ou desagradáveis, a depender de uma série de fatores. Por fim, a mensagem que composteiros costumam reforçar é que tudo vai depender do manejo do material, dado que estar amparado por algumas noções prévias pode ajudar nesse sentido, mas não é tudo.

O modo de alimentar os microrganismos para que os processos orgânicos sejam bem-sucedidos requer planejamento e participação. Ou seja, apesar da compostagem propriamente dita ser um trabalho desempenhado essencialmente por múltiplos organismos não-humanos, responsáveis por promover a degradação do material, os humanos, em diferentes etapas, exercem algumas tarefas, isto é, também participam do processo. Os guias de compostagem não dizem apenas para deixar os não-humanos trabalhar, mas chamam os humanos para a ação e para responsabilidades que envolvem: medir temperatura, dar atenção aos níveis de mistura e ao pH do solo, à aeração, à luz, aos tipos e à qualidade da comida depositada, etc. Isto é, os humanos devem cuidar da produção do ambiente no qual a compostagem se desenrola. Além disso, os manuais, como de praxe, também oferecem conselhos e dicas sobre maneiras mais eficientes de montar a lixeira de forma a reunir todas as entidades necessárias. Por esse complexo de funções, etapas e dinâmicas, a arte da compostagem não é apenas sobre atividades metabólicas dos vermes e demais microrganismos, mas muito se tem chamado atenção para a ação humana nesse processo, o que nos lembra que os processos biológicos não são, quase nunca, independentes, individuais ou exclusivos de uma única espécie ou organismo. Para que uma composteira alcance os fins almejados, os microrganismos esboçam interações interespecíficas essenciais, ao mesmo tempo que confiam nos cuidados humanos.

Quando observava a explicação de Euro e Mayan sobre compostagem, eu os via menos ensinando procedimentos técnicos e impessoais, do que descrevendo um trabalho de observação participante. No entanto, nem sempre um bom composteiro é um bom professor de compostagem; mais do que dominar o assunto, o engajamento e o empenho são cruciais para consolidação da prática no cotidiano.

Caderno Eletrônico de Ciências Sociais, Vitória, v. 8, n. 2, pp. 130-152, 2020. 
$\mathrm{Na}$ minha descrição da aula-campo, tal como os leitores poderão perceber, destaco que compostar é sobre relações, envolve unir e separar coisas. Separa-se materiais a serem compostados - há uma lista de tudo que deve ou não deve estar numa composteira - e, ao juntar o que pode ser juntado, o processo de compostagem as modifica. Essas transformações são também respostas éticas para o tempo do Antropoceno, um tempo que clama por novas políticas de relações com a terra.

Acredito poder dizer, sem grandes equívocos, que as políticas envolvidas nas artes de composto fomentam ideias sobre como viver juntos na diversidade. Um sentido que, se por um lado, remete à ética ecológica, por outro, atenta para a potência dos encontros, o que eles geram. Aqui, a analogia composto/pluriverso (cf. CADENA \& BLASER, 2018) e o entendimento de que as artes da compostagem são respostas éticas ao tempo do Antropoceno são sugestões de caminhos analíticos que nos levam direto para o plano da política, mas no sentido assemblages de política.

Manuel Delanda (2006, p. 3), procurando reconstruir e reunir a ontologia do conceito de assemblage no pensamento de Deleuze e Guattari, oferece sua própria explicação "estratégica" do termo: "a teoria da assemblage também pode ser aplicada a entidades sociais, mas o próprio fato de que ela atravessa a distinção natureza-cultura é evidência de suas credenciais realistas." ${ }^{11}$ Delanda (2006) aponta que o conceito, primeiramente, tem como rival a dialética hegeliana e o reducionismo sociológico micro-macro, característico da sociologia clássica. Neste sentido, Delanda (2006) contrasta as assemblage das totalidades ("society as a whole") e mostra que, diferentemente destas, as partes de uma assemblage não formam um todo contínuo, mas interações entre partes. A compreensão de Delanda (2006) vai ao encontro do que Isabelle Stengers (2018b, p. 105) propõe ao acionar o conceito:

Um agenciamento, para Deleuze e Guattari, é a junção de componentes heterogêneos, e tal junção é, para eles, a primeira e a última palavra da existência. Eu não existo e entro nos agenciamentos. O modo de minha existência é minha própria participação nas assembleias. Não sou dotado de agência, possuidor de intenções ou iniciativa. Animação, agência, intencionalidade, ou o que Deleuze e Guattari chamaram de 'desejo', pertencem ao agenciamento como tal. ${ }^{12}$

11 Tradução livre do original em inglês: "assemblage theory may also be applied to social entities, but the very fact that it cuts across the nature-culture divide is evidence of its realist credentials".

12 Tradução livre do original em inglês: "An assemblage, for Deleuze and Guattari, is the coming together of heterogeneous components, and such a coming together is, for

Caderno Eletrônico de Ciências Sociais, Vitória, v. 8, n. 2, pp. 130-152, 2020. 
Voltemos ao composto. Compostar é sobre união entre diferentes entidades que tornam algo possível acontecer. Para essa reflexão, as assemblages foram compostadas junto às cosmopolíticas da Isabelle Stengers (2018). As artes com minhocas de Abrahamsson e Bertoni (2014) produziram a noção de políticas de composto (compost politics) que trazem uma figuração tanto ontológica, quanto ética, mas, sobretudo, que diz respeito à prática real da compostagem. É também para o lado do trabalho sujo (dirty work) e do trabalho de cuidado (care, cf. BELLACASA, 2017), bem como o de cultivar colaborações e combinações inesperadas (HARAWAY, 2016), que estou acionando a política. Como mostram as feministas composteiras, Hamilton e Neimanis (2018), o lado sujo e invisibilizado do trabalho nos lembra de algo valioso: para que a vida seja possível alguma forma de cuidado deve ser realizada. Inspiradas por pensadoras feministas como Donna Haraway, entre outras, ${ }^{13}$ Hamilton e Neimanis (2018, p. 511) compreendem que as humanidades ambientais contemporâneas clamam por histórias ecológicas sobre cuidado que mostrem o que, afinal, está em jogo. É quando as autoras ironizam ao chamar atenção para o que consideram ser o trabalho sujo, e também invisível, desvalorizado, envolvendo o cuidado: "alguém tem que separar e esvaziar o balde de composto, por assim dizer."14

O antropólogo Sebastian Abrahamsson tem iniciado uma linha de trabalho que analisa como os alimentos e as práticas de desperdício de alimentos se relacionam na vida cotidiana. Filippo Bertoni, em sua tese em antropologia pela Universidade de Amsterdã, desenvolveu um trabalho que segue as relacionalidades das ecologias de minhocas e as maneiras pelas quais elas podem remodelar nossas noções de relação, união, política e sistemas. O trabalho deles em muito me ajudou a compreender como compostar é uma forma de engajamento cosmopolítico: "na política do composto, ao invés do cosmos, é o composto que se refere ao desconhecido constituído por esses mundos múltiplos e divergentes e às articulações das

them, the first and last word of existence. I do not exist and then enter into assemblages. The manner of my existence is my very participation in assemblages. I am not gifted with agency, the possessor of intentions or initiative. Animation, agency, intentionality, or what Deleuze and Guattari called 'desire', belong to the assemblage as such."

${ }^{13}$ Além de Donna Haraway, as autoras mencionam outras pensadoras que entrelaçam mundos-mais-que-humanos dentro de tradições feministas: Myra Hird, Vicki Kirby, Annmarie Mol, Val Plumwood, Maria Puig de la Bellacasa, Anna Tsing, dentre outras.

${ }^{14}$ Tradução livre do original em inglês: "someone has to sort and empty the compost bucket, so to speak".

Caderno Eletrônico de Ciências Sociais, Vitória, v. 8, n. 2, pp. 130-152, 2020. 
quais eles poderiam eventualmente ser capazes (Stengers, 2005, p. 995)"15 (ABRAHAMSSON \& BERTONI, 2014, p. 143).

Os autores mostram que conhecimentos emergem na prática da vermicompostagem, a qual se define por um conjunto de ações múltiplas e contingentes, mas não necessariamente harmônicas: "a política do composto não é nem a assimilação por meio da identidade nem o sonho da harmonia, mas sim uma domesticação mútua de atividades múltiplas e diferentes." (idem, p. 134). ${ }^{16}$ Compostar é sobre fusão dos alimentos e sobre prosperidade; envolve descarte de resíduos alimentares, ação de vermes e um material que é digerido para a aquisição de solo fértil como resultado final. Trata-se de uma união processual não harmoniosa que não é simplesmente forçada ou comandada pelos humanos. Ao invés disso, compostagem equivale à composição de atividades e processos diferentes, mas potencialmente convergentes.

Não podemos dizer que humanos e vermes compartilham o mesmo alimento, mas o pão velho mofado é jogado na composteira, justamente, porque não queremos mais comê-lo; já os vermes não se importam com mofo ou cascas de ovo, imagens trazidas pelos autores. Abrahamsson e Bertoni (2014) reconhecem que compostar envolve atividades metabólicas emaranhadas e complexas que reúnem diversos organismos no depósito. 0 que é reunido na caixa de compostagem está em constante atrito, mas comer, alimentar e decompor não se reduzem a esse atrito, embora contem com ele. Os autores, a partir dessas imagens, nos propõem pensar sobre como alimentar, comer e ser comido são ações divergentes que nos empurram para fora da noção ocidental naturalista sobre o que faz e o que seja o mundo natural:

\begin{abstract}
Alimentar / comer reúne diferentes atividades e 'desejos' divergentes. Ao fazer isso, permite que a multiplicidade $e$ as práticas se reúnam em eventos contínuos. Por meio da política do composto da vermicompostagem, diferentes corpos, desejos e práticas são mantidos diferentes e em tensão, em vez de serem resolvidos pelo que seria considerado 0 'bem comum'. $^{17}$ (ABRAHAMSSON \& BERTONI, 2014, p. 144)
\end{abstract}

\footnotetext{
${ }^{15}$ Tradução livre do original em inglês: "(...) in compost politics, instead of cosmos, it is compost that refers to the unknown constituted by these multiple, divergent worlds and to the articulations of which they could eventually be capable"

${ }^{16}$ Tradução livre do original em inglês: "compost politics is neither assimilation through identity nor the dream of harmony but rather a mutual domestication of multiple and different activities".

17 Tradução livre do original em inglês: "Feeding/eating brings different activities and diverging 'desires' together. In so doing, it allows for multiplicity and practices to come
}

Caderno Eletrônico de Ciências Sociais, Vitória, v. 8, n. 2, pp. 130-152, 2020. 
Vermicompostagem também nos leva à noção de espécies companheiras (companion species, HARAWAY, 2016), só que, para além das suposições de relações íntimas, amigáveis ou domesticadas dos humanos com outras espécies, pensemos em uma noção de companhia que sinaliza algo menos aconchegante e mais complexo. Ainda na perspectiva de Abrahamsson e Bertoni (2014), se a união de comer e alimentar na compostagem aproxima as diferenças, isso não resulta em torná-las semelhantes ou em fazer um mundo comum, mas em transformações e destruições que envolvem a digestão e a decomposição dos componentes. Os autores compreendem, ainda, que o mundo dentro de uma caixa de compostagem não é pré-determinado, mas envolve emergência de práticas e processos que não tratam da qualidade das relações, mas do que as relações fazem, o que elas geram.

\section{Cultura das minhocas}

No curso do PEP aprendemos com Euro e Mayan a fazer terra a partir de restos de cozinha. No caso das demandas do sítio, ter uma composteira tanto atende às necessidades de dar um destino ecológico aos resíduos orgânicos e fomentar a atividade biológica dos solos, como é um modo de alcançar maior volume de terra fértil - o que é crucial para o objetivo perseguido pelos moradores de regenerar o terreno do sítio onde vivem.

Sim. Vamos lá olhar elas! Vejam só... Esse aqui é o
minhocário do pessoal do Roots Ativa lá de BH. O que elas
fazem? Isso aqui é um sistema de compostagem usando
minhocas. É usado pra gente poder transformar, acelerar
nosso processo, gerando composto, reciclando, fechando
ciclos. Elas aceleram o processo de compostagem. A
compostagem é um mecanismo. (Euro)

A conversa é interrompida por uma minhoca. Euro deixa cair de suas mãos a minhoca que volta para dentro do minhocário. Ele a procura de novo dentro da caixa, mas rapidamente, o animal encontra uma forma de penetrar no meio da serragem. Com certa dificuldade de encontrá-la novamente, Euro decide pegar outra minhoca para apresentá-la ao grupo. Sem tirar os olhos do pequeno animal, ele comenta: "ela está cheia de ovinhos". Nos aproximamos com curiosidade para ver o animal se contorcendo em sua mão, certamente na tentativa de escapar, mas dessa vez sem muito sucesso. Neste momento, o grupo se anima e alguns fazem comentários e perguntas.

together in on-going events. Through the compost politics of vermicomposting, different bodies, desires, and practices are kept different and in tension rather than being resolved through what would be considered the 'common good'".

Caderno Eletrônico de Ciências Sociais, Vitória, v. 8, n. 2, pp. 130-152, 2020. 
Em meio às conversas, Euro pergunta se gostaríamos de pegar nela. Todos se manifestam positivamente. A minhoca foi passada de mão em mão, quando podíamos sentir sua textura, sua forma. Euro pega, agora, outra minhoca. Retirando-a da caixa, ele diz: "Olha aqui! Uma minhoca novinha, filhote". Segurando a jovem minhoquinha, ele começa sua aula trazendo algumas curiosidades sobre o mundo das minhocas e nos explica onde esse animal entra no trabalho de compostar.

As minhocas têm a capacidade de alimentar sua massa corporal oito vezes a mais por dia. A bicha come vorazmente! Por isso que a gente usa minhoca na compostagem, pra acelerar e também processar com maior qualidade o nosso composto. Ela vai alimentar aquilo ali, e aquilo ali vai digerir ali dentro do sistema digestivo dela, e vai eliminar um material muito elaborado. (Euro)

A espécie de minhoca que o casal cria em seu minhocário são as chamadas minhocas californianas. Trata-se de uma espécie exótica. Alguns dos participantes já tinham ouvido falar dessa espécie em particular, mas para mim e alguns outros presentes essa informação era uma novidade. Euro explica que, diferentemente de outras espécies, as californianas são minhocas que gostam de se alimentar de comida fresca, "ela gosta de gastronomia", ele diz, "de comida boa...". As nativas, diferentemente, são "minhocas de chiqueiro", disseram alguns dos cursistas, "a puladeira é junkie", "fedeu, ela chega".

Estabelecendo diferenças marcadas pelo comportamento e pelas preferências das espécies de minhoca, Euro segue em sua aula: "As californianas são muito amorosas, cruzam muito... se reproduzem que é uma maravilha! Se multiplicam muito e isso até se torna um problema no futuro...". Então, ele pergunta: "Por que a gente não usa outro tipo de minhoca?", e responde:

Se eu pegar uma "puladeira", nativa, e jogar ela aqui, junto com resto de comida que não está compostado, quando esse composto aquecer, elas vão morrer. As californianas suportam esse ambiente, elas gostam, se multiplicam muito mais nesse ambiente, elas se alimentam do material fresco. As minhocas nativas do solo [puladeiras], e tal, elas primeiro esperam compostar. Compostou, virou aquela terra, aí sim ela vai migrar [para a terra compostada].

Apesar das diferenças entre os tipos de minhocas e de não sabermos ao certo sobre possíveis impactos quando espécies, californianas e puladeiras, por exemplo, são colocadas para dividir um mesmo solo, o que foi explicado é que, para um processo de decomposição mais acelerado, como era o objetivo ali, as californianas seriam mais eficientes.

Caderno Eletrônico de Ciências Sociais, Vitória, v. 8, n. 2, pp. 130-152, 2020. 
Assim como há muitas formas de fazer compostagem, Euro explica, há também muitas formas de minhocultura: "Você pode fazer em containers grandes, botar vários tipos de alimentos que vão favorecer a alimentação dela. Então o que a gente está fazendo é dando alimento pra ela" (Euro). O subproduto gerado pela minhoca é usado na terra. Além de húmus, os minhocários também produzem outro subproduto, popularmente conhecido como chorume, mas que entre os permacultores recebe o nome de biofertilizante. Euro nos mostra o líquido que fica retido na parte de baixo da caixa que será, depois, utilizado em seus plantios: "Esse chorume é maravilhoso! É um biofertilizante que pode ser aplicado em vários níveis".

Encerrando a entusiasmada apresentação de suas minhocas e nos informando sobre seus vários usos e funções, Euro nos conduz para mais uma sessão do curso: a montagem da composteira. Participamos juntos de todo o processo de construção do equipamento. Fomos convidados a mover esterco, folhas secas, galhos e troncos podres, e também fomos iniciados no complexo aprendizado da arte de equilibrar carbono e nitrogênio, tudo isso pelo sucesso da compostagem. Todos os tipos de bactérias, fungos e artrópodes participam da decomposição do desperdício de alimentos. Ao lado dos vermes, outros actantes estão consumindo e quebrando a matéria orgânica na pilha de composto. Bactérias psicrofílicas ${ }^{18}$ são as primeiras a chegar. Então, conforme a temperatura aumenta por causa de sua atividade, as bactérias mesofílicas ${ }^{19}$ seguem. Estas liberam dióxido de carbono e aumentam a temperatura, abrindo caminho para bactérias termofílicas. Então, na medida que a temperatura abaixa novamente é a vez dos actinomicetos e fungos.

${ }^{18}$ Um tipo de bactéria que, quando sob temperatura ideal, é degradadora de composto.
${ }^{19}$ Ver nota anterior.

Caderno Eletrônico de Ciências Sociais, Vitória, v. 8, n. 2, pp. 130-152, 2020. 


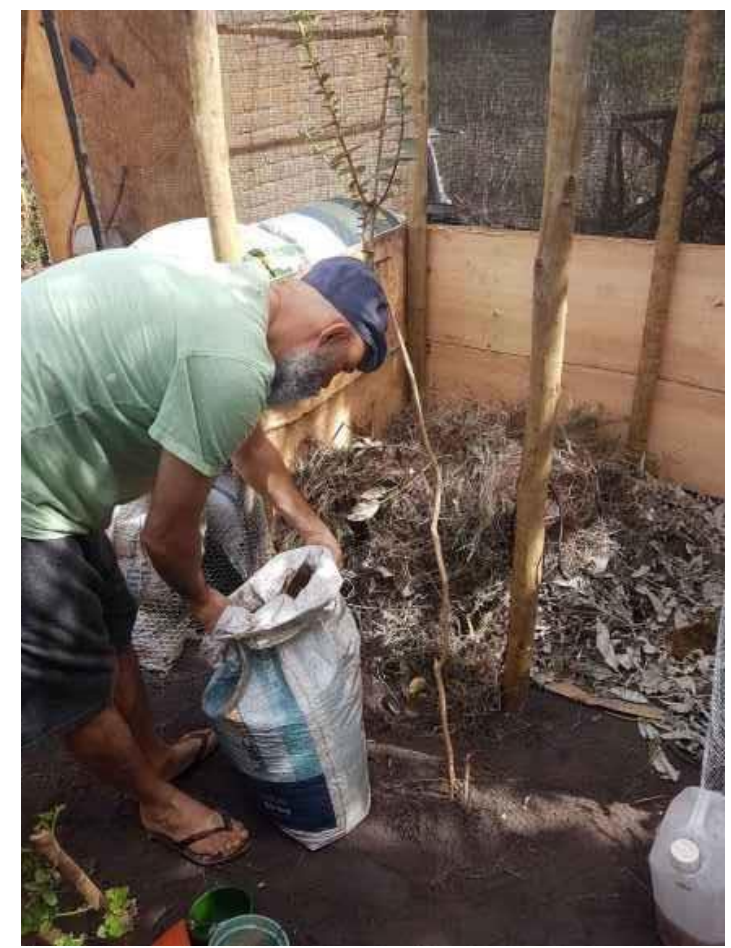

Foto 3: Adicionando materiais na composteira. Sítio Céu e Terra. Curso PEP 2019. Autoria própria.

Apesar de parecerem procedimentos mecânicos, Euro enfatiza que, na medida em que o composteiro inicia o trabalho, as etapas do manejo acabam sendo realizadas intuitivamente, "Você pode pegar com a mão, sentir a umidade, o calor, etc.", ele diz. Assim, sentir o material, se envolver com ele e fazer a observação participante são também modos de internalizar corporalmente seu funcionamento.

Encerramos esse momento do curso ao finalizar a montagem da composteira. Outras atividades sucederam ao longo desse e de demais encontros ocorridos no sítio Céu e Terra como parte da programação do PEP.

\section{Considerações finais}

A união suja e confusa que compreende o processo de compostar alimentos e materiais, como Abrahamsson e Bertoni (2014) entendem, não constrói um mundo comum do tipo que transpõe diferenças, traz semelhança, entendimento e concordância. A união que a compostagem faz é uma união política, pois está fundamentada essencialmente em diferenças. Ainda seguindo as reflexões dos autores, se a compostagem tratasse apenas de formar um mundo comum, eles dizem, os resíduos seriam apenas resíduos, e não alimentos; o material compostado seria apenas estrume, não solo. Os diferentes resultados de uniões divergentes são o que fundamentam a política da compostagem. Suas qualidades, aqui entendidas como políticas, 
estão fundamentadas nessas diferenças e é em razão dessa convivência, não necessariamente harmoniosa, que compostar é possível. São encontros nãoconvergentes, imperfeitos, e não encontros harmoniosos, entre iguais. $O$ que podemos aprender com isso?

Neste texto, optei por dar destaque ao argumento geral do curso, fundado em noções da agroecologia, assim como por discorrer sobre o que entendo como uma política mais-que-humana - quando decidi descrever a prática da compostagem. Meu objetivo com este relato não foi apresentar todo o conteúdo do curso, mas trazer a centralidade da noção de manejo e do cuidado a partir de uma perspectiva ética-ecológica e descentrada dos humanos, para a qual me instigaram os organizadores do curso.

Concentrando a descrição nessas formas de cuidado ecológico imerso, procurei mostrar que uma mudança possível nas relações humano-solo exige ecologias materiais, éticas e afetivas. Em relações de cuidado desse tipo, as ações são densas e engrossadas por multiplicidades de agentes emaranhados, os quais são envolvidos, em vez de comprimidos ou subordinados à realização linear do produtivismo. Procurei falar de transformações, sintonias entre os seres humanos e os solos multiespecíficos, ocasiões que fazem emergir novos arranjos relacionais entre espécies.

\section{Referências bibliográficas}

ABRAHAMSSON, S.; BERTONI, F. 2014. Compost politics: experimenting with togetherness in vermicomposting. Rev. Environmental Humanities, v. 4, n. 1 , pp. $125-148$.

BELLACASA, M. P. de la. Matters of Care. 2017. Speculative ethics in more than human worlds. London: University of Minnesota Press.

CADENA, M. de la \& BLASER, M. (Orgs.). 2018. A World of Many Worlds. Durham: Duke University Press.

DELANDA, M. 2006. A new philosophy of society: assemblage theory and social complexity. London: Ed. Continuum.

HAMILTON, J. M.; NEIMANIS, A. 2018. Composting Feminisms and Environmental Humanities. Environmental Humanities, v. 10, n. 2, pp. 501-527.

HARAWAY, D. 2016. Staying with the trouble. Making kin in the Chthulucene. Durham and London: Duke University Press.

KIRKSEY, E.; HELMREICH, S. 2010. The Emergence of Multispecies Ethnography. Cultural Anthropology, v. 25, n. 4, pp. 545-576. 
LATOUR, B. 2001. A Ecologia Política sem a natureza? Proj. Histórias. São Paulo (23).

LATOUR, B. 2004. Políticas da Natureza: Como Fazer Ciência na Democracia. Tradução: Carlos Aurélio Mota de Souza. Bauru, SP: EDUSC.

LATOUR, B. 2014. Anthropology at the Time of the Anthropocene - a personal view of what is to be studied. Distinguished lecture American Association of Anthropologists Washington.

PRIMAVESI, A. M. 1964. A Biocenose do solo na produção vegetal. In: $A$ moderna agricultura intensiva. Vol. 1. Santa Maria: Ed. Pallotti.

RUDOLFI, M. 2017. Living (with) the Experiment. An Ethnography of ReComposing a Future Space. Abschlussarbeit zur Erlangung des akademischen Grades Master of Arts (M.A). Goethe Universität Franffurt Am Main. Institut für Soziologie.

SANTOS, D. et al. 2017. Solos em sistemas agroecológicos. Areia (PB): Universidade Federal da Paraiba.

SOUZA, G. M. de. 2020. Envolver o que nos envolve. Permacultura e sítios ecológicos em paisagens multiespécies na Serra do Espinhaço. Tese (doutorado). Antropologia Social. Universidade Federal de Minas Gerais (UFMG).

STENGERS, I. 2018a. A proposição cosmopolítica. Revista do Instituto de Estudos Brasileiros, n. 69, pp. 442-464.

STENGERS, I. The challenge of ontological politics. In: CADENA, M. de la \& BLASER, M. (Orgs.). 2018b. A World of Many Worlds. Durham: Duke University Press.

TSING, A. L. 2019. Viver nas Ruínas: paisagens multiespécies no Antropoceno. Ed. IEB Mil Folhas. Brasília. 